\begin{tabular}{|c|c|c|}
\hline $\begin{array}{l}\text { JURNALPENELITIAN KEPERAWATAN } \\
\text { MEDIK }\end{array}$ & VOL. 1 NO. 2 & $\begin{array}{c}\text { EDITION: NOVEMBER } 2018- \\
\text { APRIL } 2019\end{array}$ \\
\hline & http://ejournal.delihusada.ac.id/index.php/JPKM & \\
\hline
\end{tabular}

\title{
HUBUNGAN FAKTOR RESIKO DENGAN KEJADIAN PADA PENYAKIT PARU OBSTRUKSI KRONIK DI PUSKESMAS MANDALA
}

\author{
Alamsyah Lukito \\ Universitas Islam Sumatera Utara, Jl. STM No. 77, Medan \\ Email: alamsyah.lukito@yahoo.com
}

\begin{abstract}
The main cause of Chronic Obstructive Pulmonary Disease is smoking or exposure to secondhand smoke from active smokers or smoke inhalation in passive smokers. Other causes are air pollution, workplace exposure, and genetic factors. This type of research is analytical research with a cross sectional approach which aims to study the existence of a variable relationship dynamics. In this study, the sample was 30 patients from the Mandala Health Center. Generally, COPD sufferers are those aged 45 years to 65 years where 21 of the 30 people suffer from risk. The chi-square test results show that there is a relationship between risk factors and the incidence of COPD in the Tembung Mandala 2018 Health Center Working Area.
\end{abstract}

Keyword: obstructive pulmonary, COPD, smoker, inhalation.

\section{PENDAhuluan}

Penyakit Paru Obstruksi Kronik (PPOK) merupakan penyakit kronik pada saluran napas yang ditandai dengan terhambatnya aliran udara khususnya udara ekspirasi dan bersifat progresif. PPOK termasuk ke dalam jenis penyakit tidak menular yang utama menurut WHO (Badan Penelitian dan Pengembangan Kesehatan, 2013).

Gejala pernapasan yang paling umum pada penderita PPOK adalah dispnea (sesak napas), dan batuk dengan atau tanpa adanya produksi sputum (dahak) (Guide \& COPD, 2017). Sembilan dari sepuluh kasus PPOK disebabkan oleh merokok (Choices, 2017). Seiring waktu, paparan zat berbahaya akan mengiritasi dan merusak paru-paru dan saluran pernapasan sehingga dapat menyebabkan PPOK yang terdiri dari bronkitis kronik dan emfisema. Penyebab utama dari PPOK adalah merokok (American Lung Association, 2017), yaitu paparan asap rokok dari perokok aktif ataupun inhalasi asap pada perokok pasif (WHO, 2016), meskipun ada juga penderita PPOK yang tidak merokok (American Lung Assosciation, 2017).

Faktor risiko yang lain yang dapat menyebabkan PPOK adalah polusi udara, paparan di tempat kerja, faktor genetik yaitu defisiensi herediter yang berat pada alfa-1 antitripsin, dan usia yang lebih tua serta jenis kelamin perempuan meningkatkan risiko terjadinya PPOK (Guide and Copd, 2017).

The Global Burden of Disease Study melaporkan prevalensi 251 juta kasus COPD secara global pada tahun 2016. Secara global, diperkirakan bahwa 3,17 juta kematian disebabkan oleh penyakit pada tahun 2015, yaitu $5 \%$ dari semua kematian secara global pada tahun itu. Lebih dari $90 \%$ kematian PPOK terjadi di negara-negara yang rendah dan menengah ke bawah. Penyebab utama COPD adalah paparan asap tembakau, baik perokok aktif atau perokok pasif (WHO,2018)

Berdasarkan data Riskesdas 2013, PPOK termasuk penyakit yang tidak menular. Prevalensi PPOK di Indonesia sebesar 3,7\%. PPOK lebih tinggi pada laki-laki (4,2\%) dibanding perempuan $(3,3 \%)$ (Badan Penelitian dan Pengembangan Kesehatan, 2013).

Indonesia memiliki 65 juta perokok atau $28 \%$ per penduduk ( $\sim 225$ miliar batang per tahun). Indonesia merupakan Negara ketiga tertinggi yang mengkonsumsi rokok (Kementrian Kesehatan, 2018). Berdasarkan data Riskesdas tahun 2013, prevalensi PPOK Di Sumatera Utara yang didasarkan pada gejala dengan usia penderita lebih dari 30 tahun adalah sebesar 3,6\% (Badan Penelitian dan Pengembangan Kesehatan, 2013).

Merokok dapat menghambat aliran udara pada saluran pernafasan secara progresif hingga 


\begin{tabular}{c|c|c}
\hline $\begin{array}{c}\text { JURNALPENELITIAN KEPERAWATAN } \\
\text { MEDIK }\end{array}$ & VOL. 1 NO. 2 & $\begin{array}{c}\text { EDITION: NOVEMBER 2018 - } \\
\text { APRIL 2019 }\end{array}$ \\
\hline & $\frac{\text { http://ejournal.delihusada.ac.id/index.php/JPKM }}{\text { REVISED: 2 MARET 2019 }}$ & \\
\cline { 2 - 3 } RECEIVED: 6 FEBRUARI 2019 & ACCEPTED: 15 APRIL 2019 \\
\hline
\end{tabular}

dapat menyebabkan perubahan struktur dan fungsi saluran pernapasan dan jaringan paru. Pada akhirnya merokok menjadi salah satu faktor penyebab risiko terjadinya PPOK (Saminan, 2014).

\section{METODE}

Jenis penelitian ini adalah penelitian analitik dengan pendekatan cross sectional. Cross sectional adalah suatu penelitian yang dilakukan dengan tujuan untuk mempelajari adanya suatu dinamika korelasi. Dilakukan dengan menggunakan pendekatan observasi dan pengumpulan data sekaligus yang dilakukan dalam waktu yang bersamaan (Notoatmojo, 2010).

Penelitian dilakukan di puskesmas mandala kecamatan medan tembung. Penelitian ini dilakukan di bulan November 2018. Populasinya adalah semua pasien PPOK yang datang memeriksakan kesehatannya dan penunggu pasien yang bukan penderita PPOK di puskesmas Mandala, dengan sampel diambil dengan metode Quota sampling yaitu Pengambilan sampel hanya berdasarkan pertimbangan peneliti saja, hanya disini besar dan criteria sampel telah ditentukan lebih dahulu. Pada penelitian ini akan di ambil sampel sebanyak 30 orang.

Metode pengumpulan data yang dilakukan dalam penelitan ini adalah dengan menggunakan data primer dan sekunder. Data primer adalah rekam medik dari puskemas Mandala. Data sekunder adalah data yang diambil dari sumber kedua. Pada penelitian ini data sekunder berupa data dari pasien PPOK di Puskemas Mandala (Imron, 2014).

Analisa data yang digunakan dalam penelitian ini adalah Analisa univariat yang bertujuan untuk menjelaskan atau mendiskripsikan karekteristik dari setiap variabel penelitian. Pada umumnya dalam analisis ini hanya menghasilkan distribusi frekuensi dan persentase dari setiap variabel dan Analisis bivariat bertujuan untuk mencari hubungan diantara dua variabel. Dalam penelitian ini digunakan uji Chi-Square. Uji Chi-Square.

\section{HASIL PENELITIAN}

Penelitian ini dilakukan di wilayah kerja puskesmas Mandala kecamatan Medan Tembung. Penelitian ini adalah penelitian analitik dengan pendekatan cross sectional.
Penelitian ini untuk melihat adalah hubungan faktor resiko dengan kejadian PPOK.

Gambaran karakteristik responden pada peneltian ini yang diamati adalah usia, jenis kelamin, faktor Resiko, dan frekuensi terjadinya PPOK. Adapun gambaran karakteristik sampel penelitian tersebut dapat dilihat pada tabel berikut :

Tabel 1. Distribusi responden berdasarkan usia

\begin{tabular}{lll}
\hline Usia & Frequensi & $\begin{array}{l}\text { Persen } \\
(\%)\end{array}$ \\
\hline 45 & 2 & 6.7 \\
49 & 1 & 3.3 \\
50 & 1 & 3.3 \\
51 & 2 & 6.7 \\
55 & 1 & 3.3 \\
60 & 7 & 23.3 \\
61 & 4 & 13.3 \\
62 & 3 & 10 \\
63 & 2 & 6.7 \\
64 & 2 & 6.7 \\
65 & 3 & 10 \\
67 & 1 & 3.3 \\
69 & 1 & 3.3 \\
\hline Jumlah & 30 & 100 \\
\hline
\end{tabular}

Tabel 1 menunjukan bahwa responden dengan usia 45 adalah 2 orang $(6,7 \%)$, usia 49 adalah 1 orang (3,3\%). Usia 40 adalah 1 orang ( $3,3 \%)$. Usia 51 adalah 2 orang ( $6,7 \%)$. Usia 55 adalah 1 orang (3,3\%). Usia 60 adalah 7 orang (23,3\%). Usia 61 adalah 4 orang $(13,3 \%)$. Uisa 62 adalah 3 orang (10\%). Uisa 63 adalah 2 orang (6,7\%). Usia 64 adalah 2 orang (6,7\%). Usia 65 adalah 3 orang (10\%). Usia 67 adalah 1 orang (3,3\%). Usia 69 adalah 1 orang (3,3\%).

Tabel 2 Distribusi responden berdasarkan jenis kelamin

\begin{tabular}{lll}
\hline $\begin{array}{l}\text { Jenis } \\
\text { Kelamin }\end{array}$ & Frekuensi & $\begin{array}{l}\text { Persen } \\
(\%)\end{array}$ \\
\hline Laki-Laki & 19 & 63.3 \\
Perempuan & 11 & 36.7 \\
\hline Jumlah & 30 & 100 \\
\hline
\end{tabular}

Dari tabel 2 didapatkan Jenis kelamin laki-laki berjumlah 19 orang $(63,3 \%)$ dan jenis kelamain perempuan 11 orang $(36,7 \%)$. 


\begin{tabular}{c|c|c}
\hline $\begin{array}{c}\text { JURNALPENELITIAN KEPERAWATAN } \\
\text { MEDIK }\end{array}$ & VOL. 1 NO. 2 & $\begin{array}{c}\text { EDITION: NOVEMBER 2018 - } \\
\text { APRIL 2019 }\end{array}$ \\
\hline & $\begin{array}{c}\text { http://ejournal.delihusada.ac.id/index.php/JPKM } \\
\text { RECEIVED: } 6 \text { FEBRUARI } 2019\end{array}$ & ACCEPTED: 15 APRIL 2019 \\
\hline
\end{tabular}

Tabel 3 Distribusi responden berdasarkan faktor resiko

\begin{tabular}{lll}
\hline Faktor Resiko & Frekuensi & $\begin{array}{l}\text { Persen } \\
(\%)\end{array}$ \\
\hline Merokok & 19 & 63.3 \\
ISPA & 3 & 10.0 \\
Terpapar Polusi & 8 & 26.7 \\
\hline Jumlah & 30 & 100 \\
\hline
\end{tabular}

Pada tabel 3 menunjukan bahwa responden dengan faktor resiko merokok adalah 19 orang $(63,3 \%)$. faktor resiko ispa adalah 3 orang $(10,0 \%)$. dan faktor resiko terpapar polusi adalah 8 orang $(26,7 \%)$.

Tabel 5.4 Distribusi responden berdasarkan terjadinya PPOK

\begin{tabular}{lll}
\hline $\begin{array}{l}\text { Terjadinya } \\
\text { PPOK }\end{array}$ & Frekuensi & $\begin{array}{l}\text { Persen } \\
(\%)\end{array}$ \\
\hline Iya & 21 & 70 \\
Tidak & 9 & 30 \\
\hline Jumlah & 30 & 100 \\
\hline
\end{tabular}

Pada tabel 4 menunjukan bahwa yang beresiko terjadinya PPOK dengan frekuensi 21 orang $(70 \%)$ dan tidak terjadinya PPOK 9 orang $(30 \%)$.

Data yang ada kemudian diuji dengan menggunakan uji bivariat dengan metode chisquare sebagai berikut.

Tabel 5 Hubungan Faktor Resiko dengan Kejadian PPOK

\begin{tabular}{lcccc}
\hline Faktor & \multicolumn{2}{c}{ PPOK } & Jumlah & P Sig. \\
Resiko & Iya & Tidak & & \\
\hline Merokok & 14 & 5 & 19 & \\
ISPA & 7 & 1 & 8 & 0.01 \\
Terpapar & 0 & 3 & 3 & \\
Polusi & & & & \\
\hline
\end{tabular}

Didapatkan hasil pada uji chi-square $p=0.01$ $(p<0.05)$ pada pengamatan melihat hubungan faktor resiko terhadap kejadian PPOK. Pada hasil yang didapat $p<0.05$ sehingga terdapat hubungan antara faktor resiko dengan kejadian PPOK di Wilayah Kerja Puskesmas Mandala 2018 Tembung.

\section{PEMBAHASAN}

Pada penelitian ini menunjukan bahwa responden dengan usia 60 adalah usia tertinggi yang mengalami PPOK sebanyak 7 orang ( $23,3 \%)$. Hasil ini sejalan dengan penelitian Fachri, 2014 dimana distribusi berdasarkan umur, didapatkan pasien PPOK stabil yang berobat ke Klinik Paru RSIJ Sukapura selama periode Maret 2013September 2014 terbanyak pada kelompok usia 60-69 tahun sebanyak 16 pasien $(37,2 \%)$ sedangkan kelompok usia terendah adalah usia 40-49 sebanyak 5 pasien (11,6\%) (Fachri, 2014).

Penderita PPOK pada penelitian ini lebih banyak pada laki-laki sebanyak $(63,3 \%)$ dan jenis kelamain perempuan 11 orang $(36,7 \%)$. Dalam Penelitian Sakti, 2014 di temukan juga bahwa subjek penelitian laki-laki memiliki prevalensi lebih tinggi dibandingkan perempuan, yaitu 37 pasien (86\%) subjek penelitian laki-laki dan 6 pasien (14\%) subjek penelitian perempuan. (Sakti, 2014)

Hasil yang didapat menunjukan bahwa yang beresiko terjadinya PPOK dengan frekuensi 21 orang $(70 \%)$ dan tidak terjadinya PPOK 9 orang (30\%). Hasil ini sama dengan penelitian Fachri, 2014 distribusi berdasarkan status perokok, pasien yang termasuk kriteria perokok memiliki presentasi yang tinggi sebanyak 38 pasien $(88,4 \%)$ sedangkan kriteria bukan perokok memiliki presentasi yang paling rendah sebanyak pasien $(11,6 \%)$ (Fachri, 2014).

Berdasarkan penelitian yang telah dilakukan ditemukan bahwa responden dengan faktor resiko merokok adalah 19 orang (63,3\%). Faktor resiko ispa adalah 3 orang $(10,0 \%)$ dan faktor resiko terpapar polusi adalah 8 orang $(26,7 \%)$. Hal ini sama dengan penelitian fachri, 2014 pasien PPOK dalam penelitian ini adalah perokok berat dengan PPOK derajat sedang sebanyak 16 pasien $(37,2 \%)$, pasien PPOK derajat sedang dengan infeksi saluran napas bawah sebanyak 15 pasien $(34,8 \%)$ serta yang disebabkan disebabkan oleh polusi luar ruangan dengan PPOK derajat sedang sebanyak 17 pasien (39,5\%) (Fachri, 2014).

Pada hakekatnya keluhan-keluhan PPOK disebabkan oleh adanya hipersekresi mucus dan sesak, yang menyebabkan penderita mengeluh batuk dan dahak serta sesak napas. Ciri-ciri jika terjadi infeksi sekunder adalah dahak yang berwarna keputih-putihan yang cenderung berwarna kelabu (karena partikelpartikel debu bila ada polusi udara). Pada stadium dini, keluhan sesak napas dirasakan jika sedang melakukan pekerjaan fisik ekstra (dyspnoe d'effort) yang masih dapat 


\begin{tabular}{c|c|c}
\hline $\begin{array}{c}\text { JURNALPENELITIAN KEPERAWATAN } \\
\text { MEDIK }\end{array}$ & VOL. 1 NO. 2 & $\begin{array}{c}\text { EDITION: NOVEMBER 2018 - } \\
\text { APRIL 2019 }\end{array}$ \\
\hline & $\begin{array}{c}\text { http://ejournal.delihusada.ac.id/index.php/JPKM } \\
\text { RECEIVED: } 6 \text { FEBRUARI } 2019\end{array}$ & ACCEPTED: 15 APRIL 2019 \\
\cline { 2 - 3 } & REVISED: 2 MARET 2019 & ACC
\end{tabular}

ditoleransi penderita dengan mudah, namun lama kelamaan sesak itu semakin progresif. Pada stadium berikutnya penderita secara fisik tak mampu melakukan aktivitas apapun tanpa bantuan oksigen, karena sambil duduk pun pasien akan tetap merasakan sesak napas (Gan, 2005).

Pada penelitian ini terdapat hubungan faktor resiko dengan kejadian PPOK, dimana faktor resiko tersebut yaitu merokok, polusi udara, dan riwayat ISPA terdapat lebih banyak pada pasien PPOK dari pada non PPOK. Hasil penelitian ini sesuai dengan penelitian Ika Nugraha, bahwa perokok dengan indeks brinkman berat mengalami PPOK derajat sedang 8 kali lebih besar dibandingkan dengan indeks brinkman berat yang mengalami PPOK ringan (Ika, 2013).

Untuk faktor resiko ISPA, penelitian ini sejalan dengan penelitian Amin, bahwa beberapa kasus PPOK termasuk derajat sedang yang ditemukan juga dapat terjadi karena infeksi saluran nafas bawah berulang (Amin, 2005). Selain itu, untuk hasil faktor resiko polusi udara hal ini sejalan dengan hasil penelitian Jati pada pekerja tambang batu kapur di Desa Darmakradenan, Kecamatan Ajibarang, Kabupaten Banyumas Tahun 2005 faktorfaktor ekstrinsik yang terbukti berhubungan dengan PPOK adalah debu (Wanda,2013).

Terapi farmakologis dilakukan untuk mengurangi gejala, mengurangi keparahan eksaserbasi dan meningkatkan status kesehatan. Setiap pengobatan harus spesifik terhadap setiap pasien, karena gejala dan keparahan dari keterbatasan aliran udara dipengaruhi oleh banyak faktor seperti frekuensi keparahan eksaserbasi, adanya gagal nafas dan status kesehatan secara umum (GOLD, 2011).

\section{KESIMPULAN}

1. Umumnya penderita PPOK adalah mereka yang berusia 45 tahun hingga 65 tahun dimana 21 dari 30 orang tersebut menderita resiko.

2. Hasil Uji chi-square menunjukkan bahwa terdapat hubungan antara faktor resiko dengan kejadian PPOK di Wilayah Kerja Puskesmas Mandala 2018 Tembung.

\section{DAFTAR PUSTAKA}

Amin M. Patogenesis dan Pengobatan Pada Penyakit Paru Obstruksi Kronik. Solo: Kongres Nasional X PDPI;2005.

Arumugam Hareesh Raj. Tingkat Pengetahuan Mahasiswa FK USU 09 tentang Merokok sebagai Faktor Resiko Utama PPOK. Medan, 2012.

Badan Penelitian dan Pengembangan Kesehatan, 2013 http://www.depkes.go.id/resources/dow nload/general/Hasil\%20Riskesdas $\% 202$ 013.pdf?opwvc $=1$ Acc esed 2018

Barnes PJ. Chronic obstructive pulmonary N Eng J Med 343. 2000. 269-80 Charoenratanakul S. Impact of COPD in the Asia-Pacific region. Presented at the 7th APSR Congress. Taipei. October 2002

Fachri Muhammad, Hubungan Faktor Risiko Merokok, Infeksi Saluran Napas Bawah, Polusi Udara dan Sosial Ekonomi dengan Berbagai Derajat PPOK Stabil di Klinik Paru Rumah Sakit Islam Jakarta Sukapur.

file:///D:/therelationbetweensmokingrisk factorlowerrespiratorytractinfectionairpol lutionandsocioeconomicwithvariousdegr eesofcopdstableatjakartaislamichospitalr sijsukapura.pdf Acc esed 2018

Gan WQ, Paul Man SF, Sin DD. 2005. The Interaction Between Cigarrette Smoking And Reduced Lung Function On Systemic Inflammation. Chest; 127: 558-564.

GOLD (Global Initiative Obstructive Lung Disease), 2009. Klasifikasi PPOK. http://www.who.int/respiratory/copd/G OLD WR 06.pdf Acc esed 2018

GOLD Inc. Pocket Guide to COPD Diagnosis, Management, and Prevention. [diakses 4 November 2011]. Di unduh dari URL: http://www.goldcopd.com/Guidelineite m.asp?|1=2\&|2=1\&intId $=989$
Guide and Copd 2017
https://goldcopd.org/wp- content/uploads/2016/12/wms-GOLD- 2017-Pocket-Guide.pdf Acc esed 2018

Ika Nugraha. Hubungan Derajat Berat Merokok Berdasarkan Indeks Brinkman 


\begin{tabular}{c|c|c}
\hline $\begin{array}{c}\text { JURNALPENELITIAN KEPERAWATAN } \\
\text { MEDIK }\end{array}$ & VOL. 1 NO. 2 & $\begin{array}{c}\text { EDITION: NOVEMBER 2018 - } \\
\text { APRIL 2019 }\end{array}$ \\
\hline & $\frac{\text { http://ejournal.delihusada.ac.id/index.php/JPKM }}{2}$ & \\
\cline { 2 - 2 } RECEIVED: 6 FEBRUARI 2019 & ACCEPTED: 15 APRIL 2019 \\
\hline
\end{tabular}

Dengan Derajat Berat PPOK. Skripsi Akper Patria Husada. https://ejournal.stikespku.ac.id/index.ph $\mathrm{p} / \mathrm{mpp} /$ article/viewFile/15/13 Acc esed 2018.

Imron Moch dan Amrul Munif . 2010. Metode Penelitian Bidang Kesehatan. Jakarta: Sagung Seto. Hal:149-154.

Kementrian Kesehatan, 2018. Perilaku merokok masyarakat Indonesia.file:///D:/infodatin-haritanpa-tembakau-sedunia\%20(1).pdf Acc esed 2018

NHLBI/WHO Initiative for Chronic Obstructive Lung Disease ( GOLD ). Global strategy for the diagnosis, management and prevention of chronic obstructive pulmonary disease Am J Respir Crit Med 163.2001.

Notoadmojo S. 2012. Penelitian kesehatan. Metodologi penelitian kesehatan. Edisi. 5. Jakarta: Rineka cipta. Hal: 101-113.

Perhimpunan Dokter Paru Indonesia, 2003. Penyakit Paru Obstruksi Kronik. https://www.klikpdpi.com/konsensus/ko nsensus-ppok/ppok.pdf [Acc esed 2018

Sakti Ali, Proporsi dan Sebaran Faktor Risiko Eksaserbasi Akut Penyakit Paru Obstruksi Kronik pada Jemaah Haji Embarkasi Jakarta Tahun 2011-2012. file:///D:/26-20-PB\%20(1).pdf [ACC esed 2018

Saminan. 2014. Efek Paparan Partikel Terhadap Kejadian Penyakit Paru Obstruktif Kronik. Idea Nursing Journal, Vol. 5 (1).

Wanda Gautami. Hubungan Kondisi Lingkungan Rumah Susun dengan Prevalensi Penyakit Respirasi Kronis di Jakarta. Skripsi Fakultas Kedokteran Universitas Indonesia Jakarta https://media.neliti.com/media/publicati ons/59443-ID-hubungan-kondisi-

lingkungan-rumah-susun.pdf Accesed $\underline{2018}$

World Health Organization 2018. Chronic obstructive pulmonary disease (COPD) http://www.who.int/respiratory/copd/en L 